\title{
Budgeting as an Instrument of Increasing Competitiveness and Sustainability of Mining Enterprise
}

\author{
Natalia Rebrowa ${ }^{1}$, Alexandr Kovalev ${ }^{1}$, Olga Frik $^{2}$, and Gaik Sargsyan ${ }^{3}$ \\ ${ }^{1}$ Financial University under the Government of the Russian Federation, Omsk Branch, 644099 \\ Partizanskaya st. 6, Omsk, Russia \\ ${ }^{2}$ Siberian Institute of Business and Information Technology, 64411624 Severnaya st., 196 bl. 1, \\ Omsk, Russia \\ ${ }^{3}$ Yerevan State University, 00251 Alex Manukyan st., Yerevan, Armenia
}

\begin{abstract}
The authors conducted a study of the concept and essence of budgeting as a financial planning tool for mining companies to secure their sustainable development. The role of budgeting in increasing the competitiveness and sustainability of the organization is shown. The importance of information on the state of budgets is shown. This information provides the company management with the opportunity to analyze the financial performance of the structural divisions of the company, identify promising areas of activity, as well as areas of differentiation of activities or structural adjustment.
\end{abstract}

\section{Introduction}

In the current economic situation in Russia, it is important to forecast critical situations and to find optimal solutions to overcome them for enterprises in order to function successfully. Therefore, it is necessary to master the methods and means of management, an integral part of which is a management accounting system.

One of the important factors of a company's commercial success is budgeting, as it helps managers responsible for a specific business process to clearly understand and fulfill the tasks assigned to them. It also helps to assess opportunities and plan their achievement on time, make necessary adjustments, and develop a resource support plan for the company.

\section{Materials and Methods}

In modern rather difficult economic realities, companies are looking for the most effective ways to control the results of the company performance for carrying out economic activities. For a successful "play" in the market, companies trying to succeed in the fight against their competitors by legal means are required to have their own strategic development plan, which reflects the goals, objectives of the company's development and ways to achieve them, taking into account possible scenarios of deviation from the plan. Budgeting also serves to overcome these unforeseen factors as painlessly as possible. 
Thus, we can say that the role of enterprise budgeting in its most general form lies in the fact that it represents the basis of:

- planning process and making management decisions;

- assessment of the financial solvency of the organization;

- motivation of employees and strengthening financial discipline.

Studies have confirmed that each company can independently assign budgeting, which will meet their requirements of the system of financial and non-financial goals, as well as objects of financial planning. At the same time, when determining the purpose of budgeting, company management should take into account that any company pursues individual goals using its own available tools.

The development of budgets within the framework of financial planning in the organization, both as a whole and in individual structural divisions, has a common goal setting target indicators of financial efficiency and effectiveness, identifying critical factors, forecasting financial results, financial substantiation of the company viability or investment projects that it implements [1].

Within the framework of budgeting, the formation and control of the state of budgets takes place according to budget objects, called financial responsibility centers. They should be divided by the types of activities and organizational structure of the company. Centers of financial responsibility are not only the points of cost - places of primary consumption of resources, but they also imply that the responsibility for achieving the established plan indicators in the field of income and expenses lies with managers. The latter, at the same time, are charged with the appropriate authority. As a result of building the financial structure, a hierarchy of financial responsibility centers arises, headed by the top manager of this system, who is responsible to the owners of the company.

Information on the state of budgets gives the company management the opportunity to analyze the financial performance of the structural units of the company, identify promising areas of activity, as well as directions for differentiating activities or structural adjustment (curtailing one activity and developing another).

Today, budgeting is a key tool of modern management, contributing to improving the efficiency of the company. Using budgeting tools, managers get the opportunity to more fully control the activities of all structural divisions of the organization, facilitate their effective interaction and direct them towards achieving common strategic goals. At the same time, budgeting provides an opportunity to predict and assess possible risks and, accordingly, promptly take the necessary measures. Of particular relevance in the context of the application of digital technologies is financial controlling and in-house budgeting, which functions include: planning cash flows; analysis of deviations of the actual financial results of organizations from planned; formation of effective management decisions; cash flow management [2].

Consequently, the introduction of budgeting will allow creating such a management system that will contribute to competitiveness, sustainable development and the achievement of the maximum effect by the organization.

\section{Results and Discussion}

Based on the foregoing, the role of budgeting and management accounting system is that it provides all the financial information of the company, reflects the movement of cash, assets and financial resources, accounts of the enterprise in the most ergonomic form, which will be clear to all users of this information who participate in management decision making process (DM). As the studies showed, for each organization, the construction of financial planning business processes, as well as the methods that are used to implement these plans and increase the efficiency of 
operations, are unique, since they are fully implemented only at a particular enterprise. Nevertheless, there are general recommendations and tools with which it is possible to standardize these processes and achieve better results.

The budgeting process is a rather complex management system; therefore, the introduction of such a system is rather lengthy and laborious process that affects a wide range of methodological, organizational and technical issues [3].

In total, there are the following units in the budget process [4]:

- analytical unit, which includes a methodology for the formation, control and analysis of the consolidated budget, a methodology for the formation of individual subbudgets;

- accounting unit, which includes the collection of market data, accounting and operational accounting;

- organizational unit, which includes the functions of divisions and the rules of their interaction;

- software and hardware unit, including software and hardware items.

There is a close relationship between these components of the budgeting process. They represent the infrastructure of the budgeting system at the enterprise. For example, at an enterprise, the place of internal document circulation can be characterized as a junction of organizational and accounting units. Moreover, on the one hand, it covers the totality of information flows that are determined by the current management accounting system. On the other hand, it is strictly enforced by internal regulations as a series of internal regulatory acts, which is part of the management system. In a generalized sense, there are five stages in the budgeting system organization at the enterprise (Fig. 1) [5].

According to Ermilova E.O., the task of the first stage is to develop a model of the structure that will allow setting goals and objectives that the organization has before the prepared budget, that is, what exactly the organization wants to achieve by budgeting [5].

According to the results of the second stage, a general scheme for the formation of the consolidated (main) budget of the company is established.

The third stage characterizes the formation of the accounting and financial policies of the enterprise. The rules for maintaining and consolidating accounting, operational and tax accounting are formed in accordance with the restrictions adopted in the preparation and monitoring of budget execution.

As part of the fourth stage, there is a development of the planning regulation, in which planning, monitoring and analysis of the reasons for non-fulfillment of budgets (factors), as well as the current regulation of budgets, should be defined and fixed.

At the fifth stage, as a result of the organization of the budgeting system, the operational and financial budgets for the planning period are compiled, a scenario analysis is carried out, the necessary adjustment of the budgeting system is carried out.

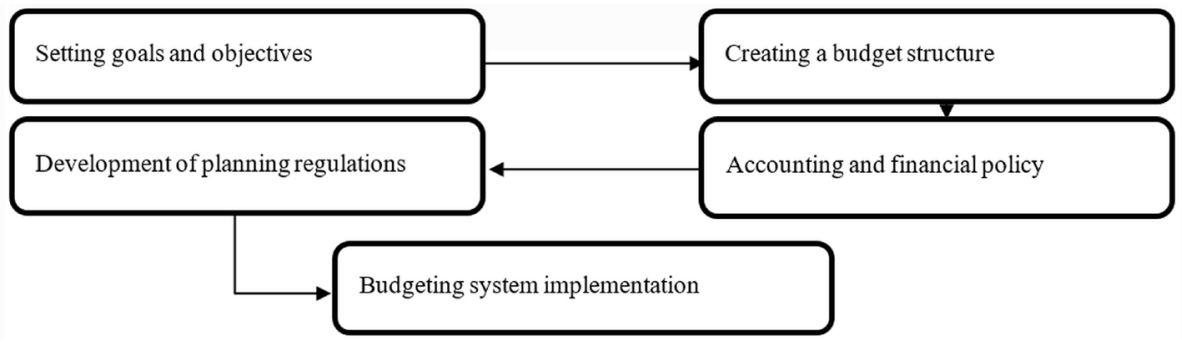

Fig. 1. Stages of development a budgeting system of mining enterprise. 
The enterprise budget is always developed for a certain time interval, which is called the budget period. The correct choice of the duration of the budget period acts as an important factor in the effectiveness of budget planning. As a rule, the duration of the budget period is one calendar year, since seasonal fluctuations in the situation are balanced over a given time period. Nevertheless, budget indicators can be set indicatively and for a longer period, that is, without bearing the target values and standards that are binding.

In the budget process, the stage of compiling a consolidated budget is not the only one. The process as a whole is a closed cycle of financial management, which consists of successive stages [6] (Fig. 2).

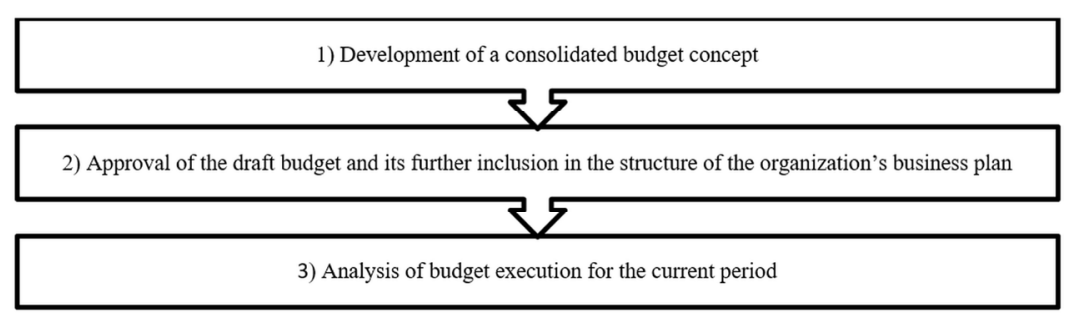

Fig. 2. The consolidated budget concept.

As part of the development of the consolidated budget concept, a preliminary draft budget is being prepared for the next planning period. Particular attention is paid to assessing the performance of planned profitability and profit indicators. For this assessment, the basis is the development of cost items that are included in the calculation of the production cost. The marketing program is being evaluated (quantitative and qualitative indicators, changes in pricing and credit policies). After that, the developed layout of the draft budget is adjusted in accordance with changes in internal and external factors.

In the process of this stage, a huge number of man-hour is spent, a large number of employees of planning and economic structural divisions are involved who carry out budget tasks: production workshops, logistics department, financial directorate, commercial directorate (sales department), etc.

At the stage of approval of the consolidated budget concept, the final draft budget is formed and then included in the structure of the business plan of the enterprise. At large enterprises, the decision to approve the consolidated budget can be taken, as a rule, by a special department of finance or planning, after which it is approved by the president of the company, the board of directors, and the meeting of shareholders. Once approved by management, the budget is already considered as a ready-made guide to action.

At the final third stage, an analysis of budget execution based on the results of the expired period takes place. The analysis of the company's financial state is carried out. On its basis the necessary adjustments are made to the strategy and tactics of economic development of the organization.

To unlock the full potential and effectiveness of the budgeting system, a number of conditions without which the system cannot function are necessary.

First, it is important for the organization to have an appropriate methodological base for the development, control and analysis of the implementation of the main budget, while company employees must be qualified enough to use this methodology in practice.

For budget development, control and analysis of its implementation, the relevant quantitative information on the organization's activities, which should be enough to evaluate comprehensively the economic activities of the enterprise (the movement of financial and inventory flows, business operations), is extremely necessary. For this, the company needs to have a management accounting system that records facts of economic activity that will fully satisfy the need for information for budgeting purposes. Therefore, 
we can say that the management accounting system is the basis of the accounting unit of the company's budgeting.

Another important factor is that budgeting does not occur in the "airless space" - it is always carried out through the management system and the corresponding organizational structure that exist in the organization [6]. This is due to the fact that the budget management system is a regulation of interaction between the company's management and structural divisions, which sets forth the responsibilities of each department and job descriptions of employees during each stage of budgeting in internal instructions and regulatory acts. The budget process is a kind of continuous and cyclical that is regular process. Accordingly, information flows of records should be routed regularly at the right time from the management and structural units.

Structural subdivisions must timely receive from the management the budget assignment and adjustments that are made to it during the budget period. Accordingly, one of the most important components of the budget process regulation is the internal document flow, which is a set of regular information flows of the enterprise divisions stated in the relevant instructions and internal acts in the process of development, monitoring and analysis of the consolidated budget execution.

The last factor is that the process of development, control and analysis of budget execution implies the registration and processing of significant amounts of information, which is extremely difficult to do manually. If we use various software and hardware, we can achieve a significant increase in the efficiency and quality of accounting and analytical work in the budgeting process, it is also possible to reduce the number of errors. These funds, which are used by the divisions of the enterprise involved in the budget process, form the basis of the software and hardware unit of the budgeting system.

One of the important factors determining the effectiveness of the implementation of the budget process is the full observance of the hierarchy of goals, targets, budgets and activities that affect several levels of management. The hierarchy of goals in this case acts as the main element. At the same time, the goals of the upper and lower levels of control must correspond to each other. Only in this way, an effective enterprise development strategy can be built. Targets, which are quantitative measures of goals, should also be linked together by a clear hierarchical relationship. However, this does not mean that all levels of management should have the same indicators. The relationship between the indicators should be built in conjunction with the economic phenomena reflected by these indicators.

\section{Conclusion}

In conclusion, it should be mentioned that the budgeting system is characterized by a comprehensive nature; it covers and coordinates the main aspects of the organization (production, marketing and finance). The budgeting management system is a regulation of interaction between company management and structural divisions, which stipulates the responsibilities of each department and job descriptions of employees during each stage of budgeting in internal instructions and regulatory acts.

At the same time, in the process of making managerial decisions at all levels, the emphasis is on the financial side, which allows maximizing profits, optimizing costs, balancing expenses with attracted financial resources, coordinating cash flows, and therefore improving the financial position of the company. 


\section{References}

1. G.K. Gabdullina, F.M. Zinnurova, Modern Society and Power, 2(12), 163-168 (2017)

2. I.V. Politkovskaya, Efficiency of performing customs operations using digital technologies and controlling (RuScience, Moscow, 2019)

3. A.V. Burov, Achievements of science and education, 6(19), 33-34 (2017)

4. V.E. Khrutsky, V.V. Gamayunov, Intrafirm budgeting: a handbook on the formulation of financial planning (Finance and Statistics, Moscow, 2017)

5. M.I. Ermilova, E.O. Azizi, M.E. Kosov, Intracorporate Financial Planning and Budgeting (Finance and Statistics, Moscow, 2018)

6. O.V. Chukhrova, Accounting and Statistics, 2 (46), 28-36 (2017)

7. V. Frolova, O. Dolina, T. Shpilkina, E3S Web Conf., 41, 04027 (2018)

8. V. Prusova, V. Beznovskay, I. Politkovskaya, E3S Web Conf., 22, 00200 (2018)

9. O. Miliushenko, A. Kovalev, M. Zhidkova, E3S Web Conf., 105, 04046 (2019)

10. O. Borisova, V. Frolova, L. Artamonova, E3S Web Conf., 105, 04047 (2019)

11. V. Frolova, O. Dolina, T. Shpilkina, E3S Web Conf., 105, 01054 (2019)

12. E. Dotsenko E., N. Ezdina, E3S Web Conf., 41, 04048 (2018) 